\title{
Positive Organizational Behavior Variables And The Effects Of Boredom Proneness On Perceived Organizational Support
}

Hatice Necla Keleş, Bahcesehir University, Vocational School, Turkey Tuğba Kıral Özkan, Bahcesehir University, Vocational School, Turkey

\begin{abstract}
The goal of this study is to emphasize the importance of "positive organizational behavior" (POB) and "boredom proneness" for businesses and to analyze their impact on employee behavior. The study is expected to show that positive organizational behavior variables have a positive explanatory power on perceived organizational support (POS) and that boredom proneness has a negative explanatory power. The study also investigates whether the organizational climate has a mediation effect on the effect of positive organizational behavior variables and boredom proneness on perceived organizational support.
\end{abstract}

Keywords: Positive Organizational Behavior; Boredom Proneness; Perceived Organizational Support; Organizational Climate

\section{INTRODUCTION}

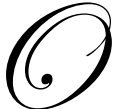

ngoing pursuits for the development and application of strategies to maximize organizational effectiveness have led to the more frequent use of concepts and theories from positive organizational science. Positive organizational science allows understanding of the effects of human behavior on organizational strategies and why certain strategies and competencies are more beneficial than others (Cameron et al., 2003). This approach is related to developments especially in the recent 5 years in positive psychology (Seligman et al., 2005) and has the objective of creating a organizational system that realizes human potential (Peterson and Spiker, 2005). Positive organizational behavior is defined as practices of the study of human resource potential and psychological capacity, which can be measured, developed and effectively geared toward performance increase in today's workplaces (Luthans et al., 2002). The psychological capacity mentioned in this definition is also referred to as "psychological capital" and is characterized as follows (Luthans et al., 2007): a) trust in one's ability to put the effort to achieve difficult tasks (self-competence), b) positive expectation for current and future success (optimism), c) display of perseverance to achieve goals (hope), d) survive in the face of challenges and difficulties and to succeed in spite of everything (endurance). If positive organizational behavior variables are to be placed in a scale, on one side can be the variable positive states of happiness, joy and content while on the other can be the relative stable characteristics, innate abilities, or negative states. Between these two extremes, on the other hand, can be the relatively improvable positive tendencies and some more-difficult-to-improve personal traits (Luthans and Avolio, 2009). The concept "boredom proneness" seen in individuals has a place in this scale that is worth analysis. Boredom proneness is defined as the individual being prone to such things as the feeling of boredom, inability to establish personal relationships, loss of enthusiasm, reduced interest in the elements that make up one's life and in the future (Sundberg et al., 1991). Studies in the literature frequently focus on the effects or consequences of being bored. Among these consequences are job dissatisfaction (Gardell, 1971), decrease in work performance (O'Hanlon, 1981, Smith, 1981), damaging the items, (Drory, 1982) and increasing rates of work accidents (Branton, 1970). In another study, Sommers and Vodanovich (2000) state that high scores of boredom proneness negatively affect mental and physical health. Results of different studies prove that there is a relationship between high scores of boredom proneness and negative outcomes (Vodanovich et al., 1991). It is determined that individuals who are often bored have higher rates of absenteeism and coming late, lower job satisfaction (Kass et al. 
2001), lower probability of completing an assigned task (Blunt and Psychyl, 2000), and higher tendency to postpone today's work to tomorrow (Vodanovich and Rupp, 1999). In general, a decrease in efficiency seems to be related to an increase in the boredom proneness (Culp, 2006).

\section{THEORETICAL FRAMEWORK AND HYPOTHESES}

Among the various factors affecting the behaviors of employees in an organization, the organization's motivators have a prominent share. Depending on the degree to which organizations value the efforts of their employees, a general perception of the organization forms in their employees (Eisenberger et al., 1986). The relationship between an organization and its employees is some kind of a relationship of mutual exchange (Rousseau, 1995), and thus, employees engage in some kind of an interchange of their efforts for the rewards they expect to obtain. One of the main components of this exchange is the concept of organizational support, which is described as an organization's support behavior perceived in the context of development, business attitudes and business outcomes (Eisenberger et al., 1986, Rhoades and Eisenberger, 2002). Among the outcomes of the concept of perceived organizational support are job satisfaction, increase in organizational commitment and organizational citizenship behavior, increase in job performance levels, and decrease in such negative attitudes as absenteeism, postponement of things-to-do, and intention to quit (Rhoades and Eisenberger, 2002; Riggle et al., 2009). An important fact indicated by studies on the subject is that perceived organizational support is equivalent in the eyes of the employees to the perception that the employer "will offer a fair pay for their efforts, will help them whenever needed, and is willing to provide favorable working conditions" (Aube et al., 2007). Acting on this idea, it is anticipated that employees' positive behaviors have a positive effect on organizational support and the following relationship is established.

H1: Positive organizational behaviors have a positive effect on perceived organizational support.

Studies in the literature show that individuals with a high boredom proneness have a lower level of perceived support from their organization compared to those with low boredom proneness (Farmer and Sundberg, 1986; Harris, 2000; Kass et al., 2001; Polly, 1993). Since a relationship is observed between the boredom proneness and negative feelings such as depression, anxiety, anger, hatred, despair, alienation, and dissatisfaction from work and life (Vodanovich, 2003), it is considered that individuals with a high boredom proneness evaluate their world relatively negatively and that this negatively affects the perceived level of organizational support. Therefore, the following relationship is projected.

H2: Boredom proneness has a negative effect on perceived organizational support.

In the 1960's, a group of Harvard Business School researchers lead by Litwin and Stringer started a study referred as the "organizational climate" with the goal of determining how people are energized, felt dedicated, and motivated by environmental factors set by their managers. This study showed that the organizational climate encouraged the employees to be more productive and to increase their job performance (Litwin and Stringer, 1968). Defined as the psychological climate that forms in an organization as a result of the individuals' interactions with their external environments (Pritchard and Karasick, 1973), the organizational climate's positive organizational behavior variables and its place in the boredom proneness is explored by the following three basic questions:

Q1: Do positive organizational behavior (POB) variables affect organizational climate?

Q2: Does boredom proneness affect organizational climate?

Q3: Can organizational climate assume the role of an intermediate variable between the effect of POB variables and boredom proneness on perceived organizational support?

\section{METHOD}

The study was implemented on the employees of a finance-sector firm operating in the Istanbul province. Company officials were contacted and the objective of the study explained to them, and the URL link to the questionnaire was sent to 250 employees via email. Of all responses, 182 were considered suitable for evaluation. 
An exploratory factor analysis of the scales yields a KMO value above of 0.70 and Bartlett's test results in significance, thereby determining that the number of data is sufficient for factor analysis.

The Perceived Organizational Support Scale (Eisenberger, 1986): Consisting of three questions, this scale was grouped into one dimension as a result of factor analysis, where the factor weights vary between 0.89 and 0.91 . Its Cronbach's alpha value was found to be 0.945 .

Organizational Climate Scale (Litwin, 1968): Consisting of three questions, this scale was grouped into one dimension as a result of factor analysis, where the factor weights vary between 0.94 and 0.96 . Its Cronbach's alpha value was found to be 0.952 .

Boredom Proneness Scale (Farmer and Sundberg,1986): Consisting of a total of 28 questions, the last 10 questions are reverse-coded. Items were grouped under one dimension. Factor weights vary between 0.50 and 0.86 , and the Cronbach's alpha value was found to be 0.943 .

Optimism Scale (Scheier and Carver, 1985): Consisting of five questions, this scale was grouped under one dimension by factor analysis. Factor weights vary between 0.62 and 0.89 . The Cronbach's alpha value was found to be 0.856 .

Hope Scale (Synder,1995): Consisting of eight questions, this scale was grouped under one dimension by factor analysis. One question was eliminated. Factor weights vary between 0.62 and 0.89 . The Cronbach's alpha value was found to be 0.799 .

Endurance Scale (Block ve Kremen, 1996): Consisting of 14 questions, this scale was grouped under one dimension by factor analysis. Four questions were eliminated as result of the analysis. Factor weights vary between 0.58 and 0.77. The Cronbach's alpha value was found to be 0.858 .

Self-Competence Scale (Schwarzer ve Jerusalem 1995): Consisting of eight questions, this scale was grouped under one dimension by factor analysis. Factor weights obtained by exploratory factor analysis vary between 0.53 and 0.86. The Cronbach's alpha value was found to be 0.832. To test the questions in the study, simple and multiple regression and hierarchic regression analyses were used.

\section{RESULTS}

As a result of the multiple linear regression analysis to test the first hypothesis, it was found that the POB variables have a significant explanatory power on POS $(\mathrm{F}=100.968, \mathrm{p}=0.000)$ and that they explain $70 \%$ of the variance of POS. Looking at the parameter values, it is observed that on an individual basis optimism, hope, and endurance are significant while self-competence is insignificant. Looking at the beta values, it is seen that "optimism" has the most important effect (0.660), followed by the "hope" variable (0.354). It is also seen that the "endurance" variable has a negative effect $(-0.215)$. In this case, the first hypothesis is partially accepted.

It was found that boredom has significant explanatory power $(\mathrm{F}=352.225, \mathrm{p}=0.000)$ and that it explains $66 \%$ of the changes in POS. Looking at the estimated parameter values, a negative effect is determined where a one unit increase in boredom causes a 0.838 unit decrease in POS. The second hypothesis is thus accepted.

Q1: Do positive organizational behavior $(\mathrm{POB})$ variables affect organizational climate?

As a result of multiple linear regression analysis, it was found that the explanatory power of the POB variables on organizational climate is significant $(\mathrm{F}=40,489, \mathrm{p}=0.000)$ and that they explain $48 \%$ of the variance. Looking at the estimated parameter values, it is seen that optimism is individually significant while hope, endurance, and self-competence are insignificant. Looking at the beta values, one unit increase in optimism increases organizational climate by 0.514 units. These findings indicate that the POB variables have an effect on organizational climate. 
Q2: Does boredom proneness effect organizational climate?

It was found that boredom proneness has a significant explanatory power $(\mathrm{F}=172,077, \mathrm{p}=.000)$ and explains $49 \%$ of the change in POS. Looking at the estimated parameter values, one unit increase in boredom-proneness results in a 0.700 unit decrease in organizational climate, indicating a negative relationship. It is concluded that boredom proneness affects organizational climate.

Q3: Can organizational climate assume the role of an intermediate variable between the effect of POB variables and boredom proneness on perceived organizational support?

At the second step of the hierarchic regression analysis, the organizational climate variable was added to the model and a $13 \%$ change in the $\mathrm{R}^{2}$ value was realized. Thereby, at the end of the second step it is seen that POB and organizational climate explains $83 \%$ of the changes in POS. Looking at the beta values, it is seen that in explaining POS the effect of the organizational climate variable is increased (0.513) and the effect of POB variables is decreased. This finding indicates that the organizational climate variable can assume an intermediate-variable role in the effect of POB on the POS variable. Related values are given in Table 1.

Table 1: Results of the Hierarchical Regression Analysis

\begin{tabular}{|c|c|c|c|c|}
\hline & & $\beta$ & $F$ & $p$ \\
\hline Model 1 & & & 100,968 & $0,000^{*}$ \\
\hline Constant Term & & 0,173 & & \\
\hline Optimism & & 0,660 & & \\
\hline Hope & & 0,354 & & \\
\hline Self-Competence & & 0,58 & & \\
\hline Endurance & & $-0,215$ & & \\
\hline$R^{2}$ after Step 1 & 0,695 & & & \\
\hline Model 2 & & & 165,844 & $0,000^{*}$ \\
\hline Constant Term & & $-0,163$ & & \\
\hline Optimism & & 0,396 & & \\
\hline Hope & & 0,178 & & \\
\hline Self-Competence & & 0,046 & & \\
\hline Endurance & & $-0,115$ & & \\
\hline Organizational Climate & & 0,513 & & \\
\hline$R^{2}$ after Step 2 & 0,825 & & & \\
\hline$\Delta R^{2}$ (Change in $R^{2}$ ) & 0,130 & & & \\
\hline
\end{tabular}

*p<0, 05; Dependent Variable: Perceived Organizational Support

Table 2: Results of the Hierarchical Regression Analysis

\begin{tabular}{|c|c|c|c|c|}
\hline & & $B$ & $F$ & $p$ \\
\hline Model 1 & & & 352,225 & $0,000 *$ \\
\hline Constant Term & & 5,592 & & \\
\hline Boredom & & $-0,838$ & & \\
\hline$R^{2}$ after Step 1 & 0,662 & & & \\
\hline Model 2 & & & 165,844 & $0,000 *$ \\
\hline Constant Term & & 2,859 & & \\
\hline Boredom & & $-0,461$ & & \\
\hline Organizational Climate & & 0,538 & & \\
\hline$R^{2}$ after Step 2 & 0,802 & & & \\
\hline$\Delta R^{2}$ (Change in $R^{2}$ ) & 0,140 & & & \\
\hline
\end{tabular}

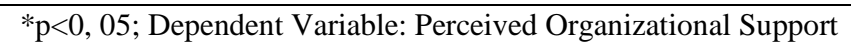


Regarding boredom proneness, at the second step of the analysis the organizational climate variable was added to the model and a $14 \%$ change in $\mathrm{R}^{2}$ occurred. Thus, it is observed that boredom proneness and organizational climate explains $80 \%$ of the changes in POS. Looking at the beta values, at the second step the effect of organizational climate in explaining POS is increased (0.538) and the effect of boredom proneness is decreased. This indicates that the organizational climate variable can assume an intermediate-variable role in the effect of boredom proneness on the POS variable. Related values are given in Table 2.

\section{CONCLUSION}

As a result of the performed analyses, it is confirmed that the POB variable dimensions "optimism" and "hope" have a significant positive explanatory power on perceived organizational support, whereas boredom proneness has a negative significant explanatory power. Employees whose optimism levels and hope increase have an increased level of perceived organizational support, while in individuals prone to boredom the perceived level of support decreases. Considering that perceived organizational support has important outcomes such as higher organizational commitment, job satisfaction, work performance and organizational citizenship behavior and lower tendency to quit the job, the importance of managers to have optimistic and hopeful and to create a positive work climate is understood better.

It is seen that there is a limited number of studies in the literature on the concepts of positive organizational behavior variables, boredom proneness, and perceived organizational support. The findings of this study are intended to contribute to management theory and application by empirically demonstrating how positive organizational behavior variables and boredom proneness affect employees' perception of organizational support. In order to clearly determine the generalizability of the results, it may be effective to conduct this study in other regions of the country and in different areas.

The phenomenon of positive organizational behavior, defined as the focus on people's strengths rather than weaknesses, is increasingly the object of research. While studies on the topic in Turkey are still limited, there is an increasing number of institutions and managers in the global business world who focus on the employees' positive behaviors instead of their negative sides aiming to converting these to productivity. Managers who expect maximum productivity from their employees by creating a positive climate in their organization are obliged to understand the strong and poor aspects of their workforce and the positive and negative behavior variables depending on their personalities, to determine the impact of these on their jobs, and to evaluate what can be done for better productivity, or, in other words, to invest in their "psychological capital".

\section{ACKNOWLEDGEMENT}

This study was presented at the $19^{\text {th }}$ National Management and Organization Conference organized by Canakkale Onsekiz Mart University during 26-28 May 2011.

\section{AUTHOR INFORMATION}

Hatice Necla Keles works as an assistant professor at Bahcesehir University, Istanbul, Turkey. She obtained her Ph.D. in Management and Organization Science in 2007 at University of Selcuk. Her research is on the subjects of entrepreneurship, organizational intelligence, job satisfaction, and organizational commitment. E-mail: necla.keles@bahcesehir.edu.tr

Tugba Kural Özkan is a lecturer at Bahcesehir University. She is currently working toward her doctoral degree in Operations Research in the Econometrics department at Marmara University, Istanbul, Turkey. Her focus is on the subjects of entrepreneurship, organizational intelligence, multivariate statistics, and structural equation models. Out of her working time, she deals with photography and has participated in group photography exhibitions. E-mail: tugba.kiral@bahcesehir.edu.tr 


\section{REFERENCES}

1. Aube, C., Rousseau, V. \& Morin, E. M. (2007). Perceived organizational support and organizational commitment: The moderating effect of locus of control and work autonomy, Journal of Managerial Psychology, 22, 479-495.

2. Block, J., \& Kremen, A. M. (1996). IQ and ego-resiliency: Conceptual and empirical connections and separateness, Journal of Personality and Social Psychology,70, 349-361.

3. Blunt, A. K. \& Pychyl, T. A. (2000). Task aversiveness and procrastination: a multi-dimensional approach to task aversiveness across stages of personal projects, Personality and Individual Differences, 28, 153-167.

4. Branton, P. (1970). A field study of repetitive manual work in relation to accidents at the workplace, International Journal of Production Research, 8, 93-107.

5. $\quad$ Cameron, K. S., Dutton, J. E. \& Quinn, R. E. (2003). Foundations of positive organizational scholarship: Foundations of a new discipline. San Francisco: Berrett-Koehler.

6. Culp, N. A. (2006). The relations of two facets of boredom proneness with the major dimensions of personality, Personality and Individual Differences, 41, 999-1007.

7. Drory, A. (1982). Individual differences in boredom proneness and task effectiveness at work, Personnel Psychology,35, 141-151.

8. Eisenberger, R., Hungtington, R., Hutchison, S. \& Sowa, D. (1986).Perceived Organizational Support, Journal of Applied Psychology, 71,500-507.

9. Farmer, R. F. \& Sundberg, N. D. (1986).Boredom Proneness-the development and correlates of a new scale. Journal of Personality Assessment, 50, 4-17.

10. Gardell, B. (1971). Alienation and mental health in the modern industrial environment. L. Levi (editor), Society, stress and disease. New York: Oxford University Press.

11. Harris, M.B. (2000). Correlates and characteristics of boredom proneness and boredom, Journal of Applied Social Psychology, 30,576-598.

12. Kass, S. J., Vodanovich, S. J. \& Callender, A. (2001). State-trait boredom: relationship to absenteeism, tenure and job satisfaction, Journal of Business and Psychology, 16, 317-327.

13. Litwin, G. H., Stringer, R. A. (1968). Motivation and Organizational Climate. Boston: Harvard Business Press.

14. Luthans, F. (2002). Positive organizational behavior: Developing and managing psychological strengths, Academic Management Executive, 16(1)57-72.

15. Luthans, F., Avolio, B.J., Avey, J.B. \& Norman, S.M. (2007). Positive psychological capital: Measurement and relationship with performance and satisfaction, Personal Psychology, 60, 541-572.

16. Luthans, F., Avolio, J. (2009).“The point of positive organizational behavior”, Journal of organizational Behavior, 291-307.Psychologica, 49, 53-82.

17. Peterson, S. J. ve Spiker, B. K. (2005). Establishing the positive contributory value of older workers: A positive psychology perspective, Organizational Dynamics, 34, 153-167.

18. Polly, L. M., Vodanovich, S.J., Watt, J. D. ve Blanchard, M. J. (1993). The effects of attributional processes on boredom proneness, Journal of Social Behavior and Personality, 8, 123-132.

19. Riggle, R. J., Edmondson, D. R. \& Hansen, J. D. (2009). A meta-analysis of the relationship between perceived organizational support and job outcomes: 20 years of research, Journal of Business Research, 62, 1027-1030.

20. Rousseau, D.M. (1995). Psychological Contracts in Organizations: Understanding Written and Unwritten Agreements. Newburry Park, CA: Sage.

21. Rhoades, L. ve Eisenberger, R. (2002). Perceived Organizational Support: A Review of the Literature. Journal of Applied Psychology, 87,698-714.

22. Scheier, M. F., ve Carver, C. S. (1985). Optimism, coping, and health: Assessment and implications of generalized outcome expectancies, Health Psychology, 4, 219-247.

23. Schwarzer, R., ve Jerusalem, M. (1995).Generalized Self-Efficacy scale. In J. Weinman, S. Wright, \& M. Johnston, Measures in health psychology: A user's portfolio. Causal and control beliefs, 35-37.

24. Seligman, M. E., Steen, T. A., Park, N. \& Peterson, C. (2005). Positive psychology progress, American Psychologist, 60, 410-421.

25. Smith, R.P. (1981). Boredom: A Review, Human Factors, 23(4) 329-340. 
26. Sommers, J. ve Vodanovich, S. J. (2000). Boredom Proneness: its relationship to psychological- and physical-health symptoms, Journal of Clinical Psychology, 56,149-155.

27. Sundberg, N. D., Latkin, C.A., Farmer, R. ve Saoud, J.(1991). Boredom in young adults: Gender and cultural comparisons, Journal of Cross-Cultural Psychology, 22, 209-223.

28. SnyderC.R., (1989): Reality Negotiation From Excusesto Hope and Beyond, Journal of Social and Clinical Psychology, 8(2)130-157.

29. Vodanovich, S. J., Verner, K.M. ve Gilbride, T.V. (1991). Boredom Proneness: its relationship to positive and negative affect, Psychological Reports, 69, 1139 -1146.

30. Vodanovich, S. J. ve Rupp, D. E. (1999). Are procrastinators prone to boredom? Social Behavior and Personality, 27, 11-16. 


\section{NOTES}

